\title{
World Journal of Pediatric Surgery \\ Analysis of the risk of ovarian torsion in 49 consecutive pediatric patients treated at a single institution
}

To cite: Sugita K, Kawano T, Motoi M, et al. Analysis of the risk of ovarian torsion in 49 consecutive pediatric patients treated at a single institution. World Jnl Ped Surgery 2019;2:e000009. doi:10.1136/ wjps-2018-000009

Received 16 August 2018 Revised 27 March 2019 Accepted 11 April 2019
Check for updates

\section{C Author(s) (or their} employer(s)) 2019. Re-use permitted under CC BY-NC. No commercial re-use. See rights and permissions. Published by BMJ.

${ }^{1}$ Department of Pediatric Surgery, Kagoshima University Graduate School of Medicine and Dental Sciences, Kagoshima, Japan ${ }^{2}$ Department of Pediatric Surgery, Kirishima Medical Center, Kirishima, Japan

Correspondence to Dr Satoshi leiri; sieiri@m.kufm. kagoshima-u.ac.jp

\section{ABSTRACT}

Purpose An early diagnosis of ovarian torsion is sometimes difficult due to variable clinical symptoms and non-specific imaging findings. We retrospectively reviewed patients with pediatric ovarian masses manifesting torsion. Methods Fifty-eight ovarian masses (55 episodes) in 49 non-neonatal patients treated from April 1984 to March 2017 were retrospectively analyzed. The Mann-Whitney $U$ test and Fisher's exact test were used for the statistical analysis.

Results The median age of these 55 episodes was 10.5 years old (range 1.0-23.0). Thirty-three patients presented with abdominal pain. Forty-five tumors and 13 cystic masses were resected and diagnosed pathologically (50 benign and 8 malignant). Torsion was identified in 15 cases $(25.9 \%)$ at operation. The torsion masses were all benign, and 8 ovaries (53.3\%) were successfully preserved. Comparing the torsion cases with the nontorsion cases, only the white cell count was significantly higher in the torsion cases $(p=0.0133)$ and in the patients presented with abdominal pain $(p=0.0068)$. The duration of abdominal pain was significantly shorter in ovary preserved cases than in oophorectomy cases.

Conclusion The white blood cell may be a helpful indicator of the presence of torsion as well as the need for surgery.

\section{INTRODUCTION}

The incidence of pediatric ovarian torsion is estimated to be 4.9 cases per 100000 girls per year. ${ }^{1}$ Half of pediatric patients with ovarian torsion are induced by an ovarian mass, including cystic and solid masses. ${ }^{2-4}$ Torsion of normal ovary, which can be caused by functional and hemorrhagic cysts, has also been reported. ${ }^{3}$ In spite of recent progress in diagnostic imaging, an early diagnosis of ovarian torsion is sometimes difficult due to variable clinical symptoms and non-specific imaging findings. ${ }^{35}$ Establishing predictive clinical pictures reflecting ovarian torsion is crucial for the diagnosis and determining the optimum therapeutic strategy to preserve its function in the current practice of pediatric surgery.
However, it often takes time for patients to consult to our institution because there are many isolated islands in our medical area. In addition, in most cases, pediatric surgeons are not the physicians performing the initial evaluation. It is therefore sometimes difficult to distinguish whether an imaging modality, such as an abdominal ultrasound examination, shows torsion or not. We started this study with the aim of obtaining simpler indicators in the primary and secondary care areas.

The aim of this study was to analyze the risk of torsion and oophorectomy of ovarian masses. We retrospectively analyzed the clinical features of 49 consecutive patients (55 episodes) with ovarian masses experienced at our institution to explore the risk factors for irreversible torsion of ovarian masses requiring oophorectomy.

\section{METHODS}

We reviewed 58 ovarian masses ( 55 episodes) in 49 non-neonatal patients treated from April 1984 to March 2017. We retrospectively analyzed the pathological diagnosis, age at admission, tumor size, white cell count at admission, C-reactive protein (CRP) level at admission, and duration of abdominal pain (from onset to surgery) based on the medical records.

\section{Statistical analyses}

Mann-Whitney U test and Fisher's exact test were used for the statistical analyses.

\section{Ethics}

This study was performed in accordance with the Ethical Guidelines for Medical and Health Research Involving Human Subjects by the Ministry of Health, Labour and Welfare of Japan in 2014 and complies with the 1964 Declaration of Helsinki (revised in 2013). It 


\begin{tabular}{|c|c|c|c|c|c|}
\hline & $\begin{array}{l}\text { Pathology } \\
(n=58)\end{array}$ & $\begin{array}{l}\text { Torsion } \\
(\mathrm{n}=15)\end{array}$ & $\begin{array}{l}\text { Non-torsion } \\
(\mathrm{n}=43)\end{array}$ & $\begin{array}{l}\text { Preservation } \\
(n=38)\end{array}$ & $\begin{array}{l}\text { Oophorectomy } \\
(n=20)\end{array}$ \\
\hline \multirow[t]{6}{*}{$\begin{array}{l}\text { Tumor } \\
(n=45)\end{array}$} & $\begin{array}{l}\text { Mature teratoma } \\
(\mathrm{n}=30)\end{array}$ & $5(3)$ & 25 (19) & 22 & 8 \\
\hline & $\begin{array}{l}\text { Immature teratoma } \\
\text { GII }(n=2)\end{array}$ & 0 & 2 & 1 & 1 \\
\hline & $\begin{array}{l}\text { Serous/mucinous } \\
\text { Adenoma }(n=5)\end{array}$ & 0 & 5 & 4 & 1 \\
\hline & $\begin{array}{l}\text { Dysgerminoma } \\
(\mathrm{n}=5)\end{array}$ & 0 & 5 & 1 & 4 \\
\hline & $\begin{array}{l}\text { Immature teratoma } \\
\text { GIII }(n=2)\end{array}$ & 0 & 2 & 2 & 0 \\
\hline & $\begin{array}{l}\text { Yolk sac tumor } \\
(n=1)\end{array}$ & 0 & 1 & 0 & 1 \\
\hline \multirow[t]{2}{*}{$\begin{array}{l}\text { Cyst } \\
(n=13)\end{array}$} & $\begin{array}{l}\text { Simple cyst } \\
(\mathrm{n}=7)\end{array}$ & $5(5)$ & $2(2)$ & 7 & 0 \\
\hline & $\begin{array}{l}\text { Hemorrhagic cyst } \\
(\mathrm{n}=6)\end{array}$ & $5(0)$ & 1 (1) & 1 & 5 \\
\hline
\end{tabular}

.0 = number of preserved ovary

GII, grade II; GIII, grade III.

was approved by the local ethics committee of our institution (No 27-119).

\section{RESULTS}

\section{Patient characteristics}

The affected ovary was on the right side in 33 episodes $(63.5 \%)$ and left in 19 episodes $(36.5 \%)$ except for synchronous bilateral lesions in three patients (three episodes). Six of the patients had bilateral pathology. Three patients had synchronous onset, and three had metachronous onset. Among the 15 cases with torsion, the affected ovary was on the right in 10 cases $(66.7 \%)$ and left in 5 (33.3\%).

The median age of the 55 episodes was 10.5 years old (range 1.0-23.0). The symptoms at the diagnosis of the 55 episodes were abdominal pain in $33(60 \%)$, and nine cases were diagnosed by chance. In the 33 episodes whose chief complaint was abdominal pain, 15 ovaries were torsed, and 18 were not torsed. The median age of the 15 patients with torsion was 9.5 years old (range 4.0-15.0). The most frequent age distribution was from 5 to 10 years of age, being seen in $46.7 \%$ of this series of 55 episodes.

\section{The pathological diagnosis and clinical outcome of the 55 ovarian masses}

The clinical outcome of the 58 ovarian masses is shown in table 1. Forty-five $(80 \%)$ masses were neoplastic tumors, and the remaining 13 were non-neoplastic tumors. Forty-five tumors were resected, and 13 cystic masses were resected or enucleated, leaving the normal ovarian tissue. All masses, regardless of pathology, were finally diagnosed after surgical intervention. The pathological diagnoses for the 58 ovarian masses were as follows: 30 mature teratomas (51.7\%), 2 immature teratomas (grade II, 3.5\%), 5 serous/mucinous cystadenomas $(8.6 \%), 2$ immature teratomas (grade III, 3.5\%), 5 dysgerminomas $(8.6 \%), 1$ yolk sac tumor $(1.7 \%), 7$ simple cysts $(12.1 \%)$, and 6 hemorrhagic cysts (10.3\%). In total, 8 malignant lesions (13.8\%), including dysgerminoma, immature teratoma (grade III), and yolk sac tumor, were confirmed.

Fifteen ovaries $(25.9 \%)$ were torsed at operation, and $43(74.1 \%)$ were not. Among the 15 torsed ovaries, 5 were tumors with solid component and the remaining 10 were cystic. There were significant differences in the torsion ratio between cystic masses and tumors including solid components $(\mathrm{p}=0.00003156)$. The pathological diagnoses of the torsed masses were as follows: five simple cysts, five hemorrhagic cysts, and five mature teratomas. Oophorectomy was performed in 20 masses, including 8 mature teratomas (40\%), 1 immature teratoma $(5.0 \%)$, 1 mucinous cystadenoma (5.0\%), 4 dysgerminoma $(20.0 \%), 1$ yolk sac tumor $(5.0 \%)$, and 5 hemorrhagic cysts $(25.0 \%)$.

\section{Clinical characteristics of patients with torsion versus non- torsion ovaries}

Clinical characteristics of patients with torsion versus non-torsion ovaries were shown in table 2 . There were no significant differences in the age, CRP value at admission, and mass size between the two groups. White cell counts on admission were significantly higher in the torsion cases $\left(10.7 \times 10^{9} / \mathrm{L}\right)$ than in the non-torsion cases $\left(6.7 \times 10^{9} / \mathrm{L}\right) \quad(\mathrm{p}=0.002)$. The cut-off white blood cell $(\mathrm{WBC})$ value for torsion was calculated to be $9.6 \times 10^{9} / \mathrm{L}$ according to receiver operating characteristic (ROC) curve analysis (figure 1). 
Table 2 Comparison of torsion masses with non-torsion masses

\begin{tabular}{lccl}
\hline & $\begin{array}{l}\text { Torsion } \\
\text { masses } \\
\text { Variables }\end{array}$ & $\begin{array}{l}\text { Non-torsion } \\
\text { masses }\end{array}$ & \\
\hline Age (years) & 9.7 & 11.6 & 0.531 \\
WBC $(/ \mu L)$ & 10360 & 6750 & 0.0327 \\
CRP $(\mathrm{mg} / \mathrm{dL})$ & 0.155 & 0.105 & 0.531 \\
Mass size $(\mathrm{cm})$ & 8 & 9 & 0.122 \\
\hline
\end{tabular}

CRP, C-reactive protein; WBC, white blood cell.

A comparison of the torsion and non-torsion masses presenting with abdominal pain is shown in table 3 . Among the 33 patients whose chief complaint was abdominal pain, $15(45.5 \%)$ were with torsion, and 18 (54.5\%) were not. There were no significant differences in the age, tumor size, CRP value at admission, or duration of abdominal pain (from onset to surgery). The white cell count on admission was significantly higher in the torsion cases $\left(10.7 \times 10^{9} / \mathrm{L}\right)$ than in the non-torsion cases $(6.5 \times$ $\left.10^{9} / \mathrm{L}\right)(\mathrm{p}=0.007)$. The cut-off WBC value for torsion was calculated to be $9.6 \times 10^{9} / \mathrm{L}$ according to ROC analysis (figure 2).

\section{Preserved versus non-preserved ovaries with torsion}

A comparison of the preserved and non-preserved ovaries with torsion is summarized in table 4 . Among the 15 masses with torsion, $8(53.3 \%)$ ovaries were successfully preserved while the other $7(46.7 \%)$ who underwent ovarian resection include oophorectomy in 3 and salpingo-oophorectomy in 4. Comparing the preserved with

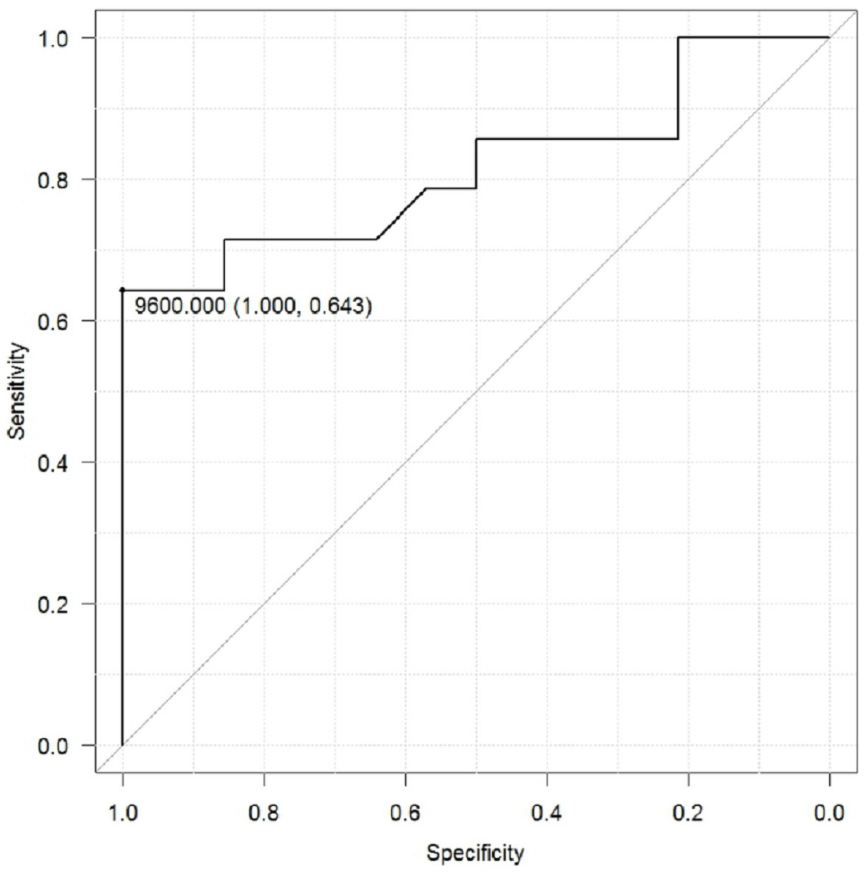

Figure 1 Receiver operating characteristic (ROC) curve for white cell count at diagnosis indicating ovarian torsion (cutoff value:9.6 $\times 10^{9} / \mathrm{L}$ at sensitivity 0.64 , at specificity 0.84 ).
Table 3 Comparison of torsion masses with non-torsion masses presenting with abdominal pain

\begin{tabular}{lccc}
\hline & $\begin{array}{l}\text { Torsion } \\
\text { masses } \\
\text { Variables }\end{array}$ & $\begin{array}{l}\text { Non-torsion } \\
\text { masses }\end{array}$ & \\
\hline Age (years) & 9.7 & 12.1 & 0.377 \\
WBC $\left(\times 10^{9} / \mathrm{L}\right)$ & 10.36 & 6.5 & 0.0257 \\
CRP $(\mathrm{mg} / \mathrm{dL})$ & 0.16 & 0.05 & 0.162 \\
Mass size $(\mathrm{cm})$ & 8 & 8.5 & 0.677 \\
Abdominal pain & 39 & 207 & 0.261 \\
lasting (hours) & & & \\
\hline
\end{tabular}

Abdominal pain lasting (hours): the duration of abdominal pain (from onset to surgery).

CRP, C-reactive protein; WBC, white blood cell.

non-preserved cases, the duration of abdominal pain was significantly shorter in the preserved cases ( 24 hours) than in the non-preserved cases (144 hours) ( $\mathrm{p}=0.026)$. The cut-off symptom duration affecting ovary preservation was calculated to 36 hours according to ROC analysis.

The radiological features regarding ovarian torsions

Nine of 15 torsion cases had available imaging data. Abdominal ultrasound sonography (US) was performed in all nine cases, and CT was also performed in 7 cases $(77.8 \%)$. We did not perform transvaginal US because of the young age of the patients. US showed 4 simple lesions (44.4\%), 5 complex lesions for hemorrhagic cysts, and mature cystic teratomas $(55.6 \%)$. Seven cases $(77.8 \%)$

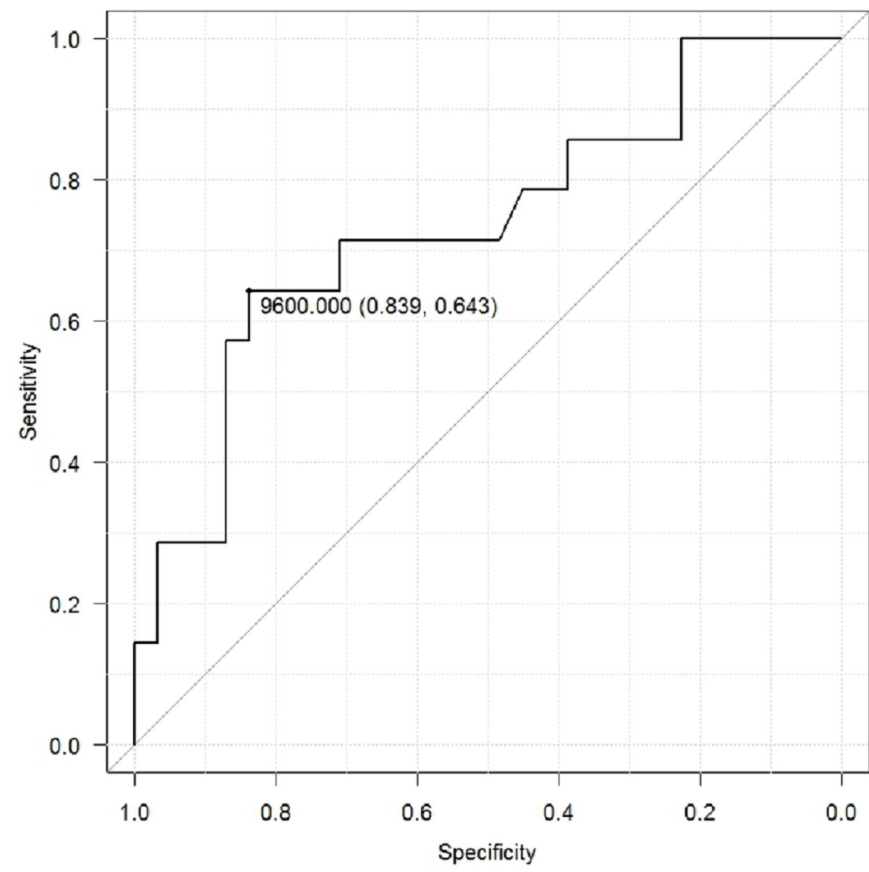

Figure 2 Receiver operating characteristic (ROC) curve for white cell count at diagnosis indicating ovarian torsion in the patients with abdominal pain (cut-off value:9.6 $\times 10^{9} / \mathrm{L}$ at sensitivity 0.65 , at specificity 1.0 ). 
Table 4 Comparison of preserved ovaries with nonpreserved ovaries with torsed masses

\begin{tabular}{lccc}
\hline Variables & $\begin{array}{l}\text { Preserved } \\
\text { ovaries } \\
(\mathbf{n}=7)\end{array}$ & $\begin{array}{l}\text { Non-preserved } \\
\text { ovaries } \\
(\mathbf{n}=7)\end{array}$ & P value \\
\hline Age (years) & 10.0 & 9.6 & 0.456 \\
\hline WBC (x 109/L) & 9.6 & 12.55 & 0.295 \\
CRP (mg/dL) & 0.095 & 0.34 & 0.149 \\
Mass size (cm) & 8 & 7.4 & 0.306 \\
$\begin{array}{l}\text { Abdominal pain } \\
\text { lasting (hours) }\end{array}$ & 24 & 144 & 0.027 \\
\hline
\end{tabular}

Abdominal pain lasting (hours): the duration of abdominal pain (from onset to surgery).

CRP, C-reactive protein; WBC, white blood cell.

showed ovarian fluid retention or edema of a fallopian tube or ovary. There was only one case in which the blood flow in the ovary was evaluated by color Doppler US, and a normal blood flow was noted.

\section{Surgical procedure for ovarian tumor}

The surgical procedure was laparotomy in $37(67.3 \%)$ and laparoscopy in $18(32.7 \%)$. Laparoscopy was introduced at our institution in 2006, after which point 14 of 32 episodes $(43.8 \%)$ underwent laparoscopy-assisted surgery. Five cases were converted to open oophorectomy by a Pfannenstiel incision. Surgery was planned in $65.5 \%$ and performed emergently in $34.5 \%$. Teratomas and simple cysts are treated with enucleation by laparoscopic surgery or laparotomy with a Pfannenstiel incision, whereas malignant tumors are subjected to oophorectomy by laparotomy or laparoscopy.

\section{DISCUSSION}

Abdominal pain with unilateral ovarian enlargement should always be suspected to indicate ovarian torsion in girls. ${ }^{67}$ In general, the precise diagnosis of torsion is based on enhanced CT findings. ${ }^{8}$ However, pediatric outpatient clinics do not always have access to such imaging modalities especially in a district hospital or in remote islands. We therefore analyzed the basic components of clinical findings that suggest ovarian torsion for a timely transfer to the tertiary center where pediatric surgery is available.

The most common symptom of ovarian torsion is abdominal pain. In our case of ovarian torsion, sudden abdominal pain $(100 \%)$ and vomiting (20\%) were characteristic. Although the strength of abdominal pain ranged from very strong and sharp to dull or mild pain, all cases reported a sudden onset. In contrast, there were no cases with chief complaints of a fever; furthermore, while the white cell count was increased (median 10.7 (range 5.2 to 18.2 ) $\times 10^{9} / \mathrm{L}$ ), the elevation was only slight. Therefore, a differential diagnosis from gastrointestinal diseases, such as appendicitis and acute gastroenteritis, is necessary. Gastrointestinal disease is usually accompanied by inflammation and a high white cell count. In the case of acute appendicitis, abdominal pain gradually becomes stronger, and there are many cases with fever (64\%) and vomiting $(42.4 \%)$ than ovarian torsion. ${ }^{9}$ In addition, the white cell count is about $13.0 \times 10^{9} / \mathrm{L}$, which tends to be higher than ovarian torsion. ${ }^{10}$

Comparing the torsion and non-torsion ovaries presenting with abdominal pain, Rey-Bellet Gasser et al reported that laboratory tests were not helpful for diagnosing the torsion of ovarian masses, ${ }^{5}$ while Graif and Itzchak reported that the white cell count is high in cases of torsed ovarian masses. ${ }^{11}$ Our results suggest that only white cell count may be helpful for detecting torsion. A white cell count of $>9.6 \times 10^{9} / \mathrm{L}$ may indicate torsed ovarian masses, and it may be best at least to perform laparoscopic exploration. The white cell count was significantly higher in the torsion cases than in the non-torsion cases $(p=0.0133)$ and the cut-off value was $9.6 \times 10^{9} / \mathrm{L}$. White cell counts may help decide if surgery is indicated in cases of suspected ovarian torsion.

The majority of ovarian torsion occurred to the ovarian cyst. Regarding the mass size, Huchon et al reported that ovaries with cysts $>5 \mathrm{~cm}$ carry a risk of torsion. ${ }^{12}$ However, Warner et al reported conversely that size and the character of ovarian cysts had no relationship with torsion. ${ }^{13}$ In our study, there were no significant differences in the mass size between torsed and non-torsed masses. Regarding tumor pathology, benign ovarian masses carry a higher risk of torsion than malignant masses. ${ }^{14}$ In our study, all of the torsed masses were found to have benign pathology. The detailed pathology of the torsed masses showed mature teratomas and cystic masses. Furthermore, mature teratomas included tumors with large cystic components. We therefore considered cystic tumors to have a higher risk of torsion than ovarian tumors with solid components. Most malignant ovarian masses have a solid component with invasive growth. As a result, an adhesive tumor biology leads to a low risk of torsion in malignant ovarian masses.

Oophorectomy was performed in 20 masses. Regarding dysgerminoma, there was one case in which a laparoscopic biopsy was performed to evaluate the possibility of recurrence. With the exception of this one case, we performed oophorectomy in all dysgerminoma and yolk sac tumor. For teratomas, regardless of maturity, we limited the surgery to nuclear excision or partial resection that preserved the ovary as much as possible. However, in this long-term study, we found that oophorectomy had been performed for eight mature teratomas and five hemorrhagic cysts. Regarding torsed ovaries, the normal function has been shown able to be restored following detorsion. ${ }^{15}$ Oophorectomy should therefore be avoided except in cases of thromboembolism, peritonitis, and malignancy. ${ }^{6}$ Five hemorrhagic cysts were resected in the earlier period of this series. We should try to preserve even necrotic-appearing ovaries that were black-blue in color.

In conclusion, the white cell count may therefore be a helpful indicator of the presence of torsion as well as 
the need for surgery, and the cut-off white cell count was $9600 / \mu \mathrm{L}$ in all ovarian masses and $9600 / \mu \mathrm{L}$ in ovarian masses with abdominal pain.

Acknowledgements We thank Mr Brian Quinn for his comments and help with the manuscript.

Contributors KS drafted this manuscript. TK, MM and TM revised the manuscript. SO, TM, KY, WY and KS collected the data. RM, SM, KN and KS analyzed and interpreted the data.TK, KS and SI designed this study. All authors read and approved the final manuscript.

Funding The authors have not declared a specific grant for this research from any funding agency in the public, commercial or not-for-profit sectors.

Competing interests None declared.

Ethics approval The Ethics Committee of Kagoshima University (№ 27-119).

Provenance and peer review Not commissioned; externally peer reviewed.

Data sharing statement Data are available upon reasonable request.

Open access This is an open access article distributed in accordance with the Creative Commons Attribution Non Commercial (CC BY-NC 4.0) license, which permits others to distribute, remix, adapt, build upon this work non-commercially, and license their derivative works on different terms, provided the original work is properly cited, appropriate credit is given, any changes made indicated, and the use is non-commercial. See: http://creativecommons.org/licenses/by-nc/4.0/.

\section{REFERENCES}

1. Schuh AM, Klein EJ, Allred RJ, et al. Pediatric adnexal torsion: not just a Postmenarchal problem. J Emerg Med 2017;52:169-75.

2. Servaes S, Zurakowski D, Laufer MR, et al. Sonographic findings of ovarian torsion in children. Pediatr Radiol 2007;37:446-51.

3. Bertozzi M, Esposito C, Vella C, et al. Pediatric ovarian torsion and its recurrence. J Pediatr Adolesc Gynecol 2016;30:413-7.

4. Rody A, Jackisch $C$. The conservative management of adnexal torsion. Eur J Obstetr Gynecol and Repr Biology 2002;101:83-6.

5. Rey-Bellet Gasser C, Gehri M, Joseph J-M, et al. Is it ovarian torsion? A systematic literature review and evaluation of prediction signs. Pediatr Emerg Care 2016;32:256-61.

6. Ngo AV, Otjen JP, Parisi MT, et al. Pediatric ovarian torsion. Pediatr Radiol 2015;45:1845-55.

7. Shadinger LL, Andreotti RF, Kurian RL. Preoperative sonographic and clinical characteristics as predictors of ovarian torsion. $J$ Ultras Med 2008;27:7-13.

8. Oltmann SC, Fischer A, Barber R, et al. Cannot exclude torsion. J Pediatr Surg 2009;44:1212-6.

9. Bundy DG, Byerley JS, Liles EA, et al. Does this child have appendicitis? JAMA 2007;298:438-51.

10. Buyukbese Sarsu S, Sarac F. Diagnostic value of white blood cell and C-reactive protein in pediatric appendicitis. Biomed Res Int 2016;2016:1-6

11. Graif M, Itzchak Y. Sonographic evaluation of ovarian torsion in childhood and adolescence. AJR Am J Roentgenol 1988;150:647-9.

12. Huchon C, Staraci S, Fauconnier A. Adnexal torsion. Human Reprod 2010;25:2276-80.

13. Warner BW, Kuhn JC, Barr LL. Conservative management of large ovarian cysts in children. Surg 1992;112:749-55.

14. Childress KJ, Dietrich JE. Pediatric ovarian torsion. Surg Clin North Am 2017;97:209-21.

15. Geimanaite L, Trainavicius K. Ovarian torsion in children. J Pediatr Surg 2013;48:1946-53. 